\title{
Animal Cell Mutants Represent Two Complementation Groups of Peroxisome-defective Zellweger Syndrome
}

Nobuyuki Shimozawa, ${ }^{\star *}$ Toshiro Tsukamoto, ${ }^{\star}$ Yasuyuki Suzuki, ${ }^{\star}$ Tadao Orii, ${ }^{\star}$ and Yukio Fujiki

${ }^{*}$ Meiji Institute of Health Science, Odawara 250, Japan; and ${ }^{\ddagger}$ Department of Pediatrics,

Gifu University School of Medicine, Gifu 500, Japan

\begin{abstract}
Generalized peroxisome-deficient disorders including cerebrohepato-renal Zellweger syndrome, neonatal adrenoleukodystrophy, and infantile Refsum disease are autosomal recessive diseases, where catalase-containing particles (peroxisomes) are morphologically absent. We previously isolated two Chinese hamster ovary (CHO) cell mutants ( $\mathrm{Z24}$ and $\mathrm{Z65}$ ) that resemble the fibroblasts from patients with such diseases, in their defective peroxisome assembly (Tsukamoto, T., S. Yokota, and Y. Fujiki. 1990. J. Cell Biol. 110:651-660). Here we report isolation by the $\mathrm{P9OH} / \mathrm{UV}$ method of a peroxisome-deficient CHO mutant, ZP92, of the third complementation group distinct from those of Z24 and Z65. Peroxisomal membrane ghosts were noted by immunochemical staining in all of the CHO mutants. Complementation analysis by cell fusion of the CHO mutants with cultured fibroblasts from patients with generalized peroxisomal disorders revealed that two CHO mutants (Z24 and ZP92) represent the human complementation groups, $E$ (the same as group 1 in the U.S.) and $C$ (the same as group 4), respectively. These CHO cell mutants are an apparently relevant animal cell model for studies on the molecular bases and primary defects of human peroxisome-deficient diseases. (J. Clin. Invest. 1992. 90:1864-1870.) Key words: Chinese hamster ovary cell $\bullet$ mutant selection - complementation analysis $\bullet$ organelle deficiency $\bullet$ autosomal recessive disease
\end{abstract}

\section{Introduction}

Peroxisome is an ubiquitous intracellular organelle bounded by a unit membrane in eukaryotes, yeast to human, and functions in essential metabolic pathways including $\beta$-oxidation of very long chain fatty acids and synthesis of etherglycerolipids, such as plasmalogen $(1,2)$. Human peroxisome-deficient dis-

Please address correspondence to Dr. Yukio Fujiki, Meiji Institute of Health Science, Odawara 250, Japan. T. Tsukamoto's present address is Department of Life Science, Himeji Institute of Technology, Kamigori, Hyogo 678-12, Japan. 1992.

Received for publication 4 March 1992 and in revised form 26 May

1. Abbreviations used in this paper: AOx, acyl-CoA oxidase; $\mathrm{CHO}$, Chinese hamster ovary; DHAP-ATase, dihydroxyacetonephosphate acyltransferase; IMP, peroxisomal integral membrane protein; PAF-1, peroxisome assembly factor-1; P12, 12-(1'-pyrene)dodecanoic acid $\mathrm{P9OH}$, 9-( ('-pyrene)nonanol; $\mathrm{TG}^{\mathbf{r}}$, 6-thioguanine resistant; thiolase, 3-ketoacyl-CoA thiolase; ZS, Zellweger syndrome.

J. Clin. Invest.

(c) The American Society for Clinical Investigation, Inc.

0021-9738/92/11/1864/07 \$2.00

Volume 90, November 1992, 1864-1870 orders are autosomal recessive $(2,3)$ and include at least eight different genotypes thus far reported (4-6), with three distinct phenotypes of diseases; i.e., cerebro-hepato-renal Zellweger syndrome (ZS), ${ }^{1}$ neonatal adrenoleukodystrophy, and infantile Refsum disease (1-3). Goldfischer et al. (7) reported that no peroxisome was observed in electron microscopy of the liver and kidney from patients with Zellweger syndrome. Recent findings are consistent with the notion that these disorders are closely or tightly linked to the dysfunction of peroxisomes, which causes anomalies including accumulation of very long chain fatty acids in body fluid and very low level of plasmalogen in various tissues, such as the brain and erythrocytes (1-3). Santos et al. (8) and Wiemer et al. (9) noted apparently empty peroxisomal membrane vesicles, "membrane ghosts," in fibroblasts from Zellweger patients by immunoelectron microscopic analysis using antibody to peroxisomal membrane protein, suggesting that import of peroxisomal proteins is impaired in these patients.

In general, it is not an easy task to work with specimens from patients and manipulate the cells (even the fibroblasts) in investigation of the pathogenesis and molecular bases for primary defects of these disorders. For such purposes, mammalian somatic cell mutants that resemble both phenotypically and genotypically the cells from the patients would be useful. By screening from Chinese hamster ovary ( $\mathrm{CHO}$ ) cells, such mutants with peroxisomal dysfunctions have been isolated: two mutually different mutants (Z24 and Z65) from our laboratory (10) and several mutant clones of one complementation group (11). Zoeller et al. (11) noted by cell fusion analysis that genetic lesion of their mutants differed from those of two complementation groups of ZS patients. By means of cDNA transfection followed by genetic complementation assay, we isolated a cDNA encoding peroxisome assembly factor-1 (PAF-1) that restores the assembly of peroxisomes and complements the abnormalities in the CHO mutant Z65 (12). Here, we report a CHO mutant ZP92 that is defective in peroxisome formation, phenotypically similar to but genotypically distinct from Z24 and Z65. By a complete set of complementation analyses among three $\mathrm{CHO}$ mutants and eight groups of fibroblasts from patients with generalized peroxisomal disorders such as ZS, two CHO mutants, Z24 and ZP92, were revealed to be respectively in the same complementation group of two genotypically separate ZS patients. These $\mathrm{CHO}$ mutants appear to be potent somatic cell models for human peroxisome-deficient disorders.

\section{Methods}

Selection of peroxisome-deficient $\mathrm{CHO}$ cell mutants. $\mathrm{CHO}$ cells treated with ethylmethane sulfonate ( 10 ) were grown in F12 with $10 \%$ FCS for $1 \mathrm{~d}$. The growth medium was changed to the F12-containing $10 \%$ FCS and $6 \mu \mathrm{M}$ 9-(1'-pyrene)nonanol (P9OH) (13) and the cells were fur- 


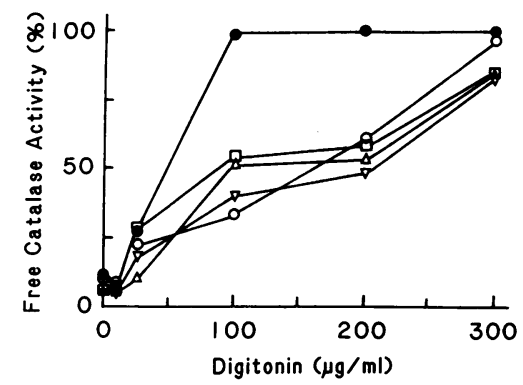

Figure 1. Latency of catalase in wild type, mutant, and hybrid $\mathrm{CHO}$ cells. Relative free catalase activity was measured in the presence of digitonin (10). (0) wild type; $(\bullet)$ a mutant ZP92; $(\nabla)$ hybrid cells, ZP92 $\times$ wildtypeTGrouar; $(\Delta)$

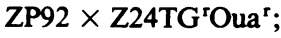
and (口) ZP92 $\times$ $\mathrm{Z}^{2} 5 \mathrm{TG}^{\mathrm{r}} \mathrm{Oua}^{\mathrm{r}}$.

ther cultured for $20 \mathrm{~h}$. The cells were washed once with $\mathrm{F} 12$ and incubated for $6 \mathrm{~h}$ in F12 with 10\% FCS. After thoroughly washing the cells with $\mathrm{F} 12$, mutants deficient in peroxisomes were selected by 2-min exposure to ultraviolet (UV) light, according to Morand et al. (13).

Assays. Dihydroxyacetonephosphate acyltransferase(DHAP-ATase), latency of catalase, and resistance to 12-(1'-pyrene)dodecanoic acid (P12)/UV treatment were measured as described $(10,12)$.

Morphological analysis. Peroxisomes in CHO cells were detected by indirect immunofluorescence light microscopy (14) using rabbit antibody to rat liver catalase (10) and rabbit antiserum to $70 \mathrm{kD}$ peroxisomal integral membrane protein ( 70 IMP) (10), and those in human fibroblasts were detected with rabbit anti-human catalase antibody (14). Antigen-antibody complex was detected with FITC-labeled goat anti-rabbit IgG antibody (Bio-Rad Laboratories, Richmond, CA).

Cell-fusion and labeling of protein. Parent cells and the cells to be examined were cocultured for $1 \mathrm{~d}$ and then fused with the use of polyethylene glycol as described (10). Cell fusion of 6-thioguanine resistant $\left(\mathrm{TG}^{\mathrm{r}}\right)$ variants of $\mathrm{CHO}$ cell mutants with human fibroblasts were also done as described (11), except that selection of fused cells was carried out with $1 \mu \mathrm{M}$ ouabain. Metabolic cell labeling for $48 \mathrm{~h}$ with $\left[{ }^{35} \mathrm{~S}\right]-$ methionine and immunoprecipitation from cell lysates of peroxisomal proteins were done as described (10).

\section{Results}

Isolation and complementation analysis of peroxisome-deficient $\mathrm{CHO}$ cell mutants. We isolated eight independent clones of $\mathrm{CHO}$ cell mutants by the $\mathrm{P} 9 \mathrm{OH} / \mathrm{UV}$ selection procedure. Complementation group analysis of these mutants was carried out by cell fusion followed by measurement of catalase latency with digitonin. Full catalase activity of a mutant ZP92 was detected at $100 \mu \mathrm{g} / \mathrm{ml}$ of digitonin, as previously noted in Z24 and Z65 cells (10), whereas nearly $65 \%$ of the catalase remained latent in the wild type $\mathrm{CHO}$ cells (Fig. 1). Treatment with $300 \mu \mathrm{g} / \mathrm{ml}$ of digitonin released $100 \%$ activity from the wild type cells. Upon the treatment with digitonin, fusion of ZP92 with the wild type cells showed the same profile of catalase latency as seen in the wild type cells, accordingly indicating that the mutation in ZP92 is recessive. Catalase of the ZP92 became latent, close to the wild type, after fusion with $Z 24$ or $\mathrm{Z65}$, thereby indicating that the genotype of ZP92 was distinct from those of Z24 and Z65. All of the other seven mutants isolated were complemented in catalase latency by fusion with $\mathrm{Z} 24$, but not with $\mathrm{Z} 65$, suggesting that these mutants are in the same complementation group as the Z65 (not shown).

Wild type, mutant, and hybrid $\mathrm{CHO}$ cells were stained with anticatalase antiserum and FITC-labeled second antibody. Catalase was detected in a diffused manner, evidently in the cytosol in all of the mutants, Z24, Z65, and ZP92, whereas it was in

numerous particles, presumably peroxisomes, in the wild type cells (Fig. $2 \mathrm{~A}$ ). Fused cells of ZP92 with Z24 and Z65, respectively, showed catalase-positive particles as numerous as in the wild type. The results are compatible with the findings in the catalase latency test, strongly suggesting that ZP92 belongs to the third complementation group different from those of Z24 and $\mathrm{Z65}$.

CHO cell mutants were stained with antiserum against 70 IMP (Fig. 2 B). Punctate staining pattern was noted in the wild type cells, as seen with anticatalase antibody. Larger but fewer particles immunoreactive with anti-70 IMP antibody were detected in all of the mutants, similar to those "peroxisomal ghost"-like vesicles seen in the fibroblasts from Zellweger patients $(8,9)$.

The CHO mutant ZP92 was defective in DHAP-ATase and sensitive to the P12/UV treatment (Table I). After selection by the P9OH/UV method, 90\% of ZP92 cells survived, but only $<0.001 \%$ of the wild type CHO cells were viable. All findings were also evident in the mutants Z24 and Z65.

Biogenesis of peroxisomal enzymes was investigated in the mutant ZP92 and its hybrids with Z24 and Z65, respectively, that had been labeled with [ ${ }^{35} \mathrm{~S}$ ] methionine. Acyl-CoA oxidase (AOx), the first enzyme of peroxisomal $\beta$-oxidation system, is a hetero-dimer comprising 75-kD A, 53-kD B, and 22-kD C polypeptide components $(10,15) ; B$ and $C$ are derived from $A$ $(16,17)$. All of three ${ }^{35}$ S-polypeptide components were evident in the wild type $\mathrm{CHO}$ cells (Fig. 3, lane 5) with a faint band of $\mathrm{C}$ attributed to the low content of methionine $(10,15)$, whereas the reduced $75-\mathrm{kD}^{35} \mathrm{~S}-\mathrm{A}$ form of $\mathrm{AOx}$, but not converted forms (53-kD B and 22-kD C components) was detected in ZP92 because of a rapid degradation, as noted in the Z24 and Z65 (10) (Fig. 3, lane 6). The third enzyme, 3-ketoacyl-CoA thiolase (thiolase), is synthesized as a larger precursor of $44-\mathrm{kD}$, then processed to a $41-\mathrm{kD}$ mature form $(10,16,18)$. Only a $44-\mathrm{kD}^{35} \mathrm{~S}$-precursor of thiolase was detectable in $\mathrm{ZP92}$, consistent with the finding in Z24 and Z65 (10), although the 41-kD mature protein was apparent in the wild type cells (Fig. 3, lanes $I$ and 2). In the hybrid cells of ZP92 with Z24 and Z65, respectively, appropriate processing of $\mathrm{AOx}$ and thiolase was evident, as in the wild type (lanes $3,4,7$, and 8 , respectively). These results accordingly support a notion that a $\mathrm{CHO}$ mutant ZP92 belongs to a complementation group distinct from those of Z24 and $\mathrm{Z65}$.

Analysis of cell fusion with fibroblasts from Zellweger patients. Next, we searched for by cell fusion and staining with anticatalase antibody, human fibroblasts from ZS patients that belong to the same complementation group as each of the CHO mutants. Numerous punctate catalase-containing structures, peroxisomes, were noted in the fibroblasts from a control, whereas catalase was stained in a diffused manner in the cytosol of the fibroblasts from patients with ZS and neonatal adrenoleukodystrophy who belonged to complementation groups B and C (the same as group 4 in the U.S.), and E (group 1 in the U.S.) (Fig. 4, $a-d$ ). Cytosolic catalase was also noted in fibroblasts from ZS patients of the other groups, A, D, 2, 3, and 6 (not shown). All combinations of cell fusion between three $\mathrm{CHO}$ mutants and fibroblasts were done and the hybrid cells were also stained for catalase ( Table II). All cell hybrids except two contained peroxisomes, suggesting that they are each in different complementation groups, as represented in Fig. 4 ( $e-$ $g$, and $j$ ). Peroxisome-negative were the cell hybrids of ZP92 and Z24 with fibroblasts from patients of complementation 

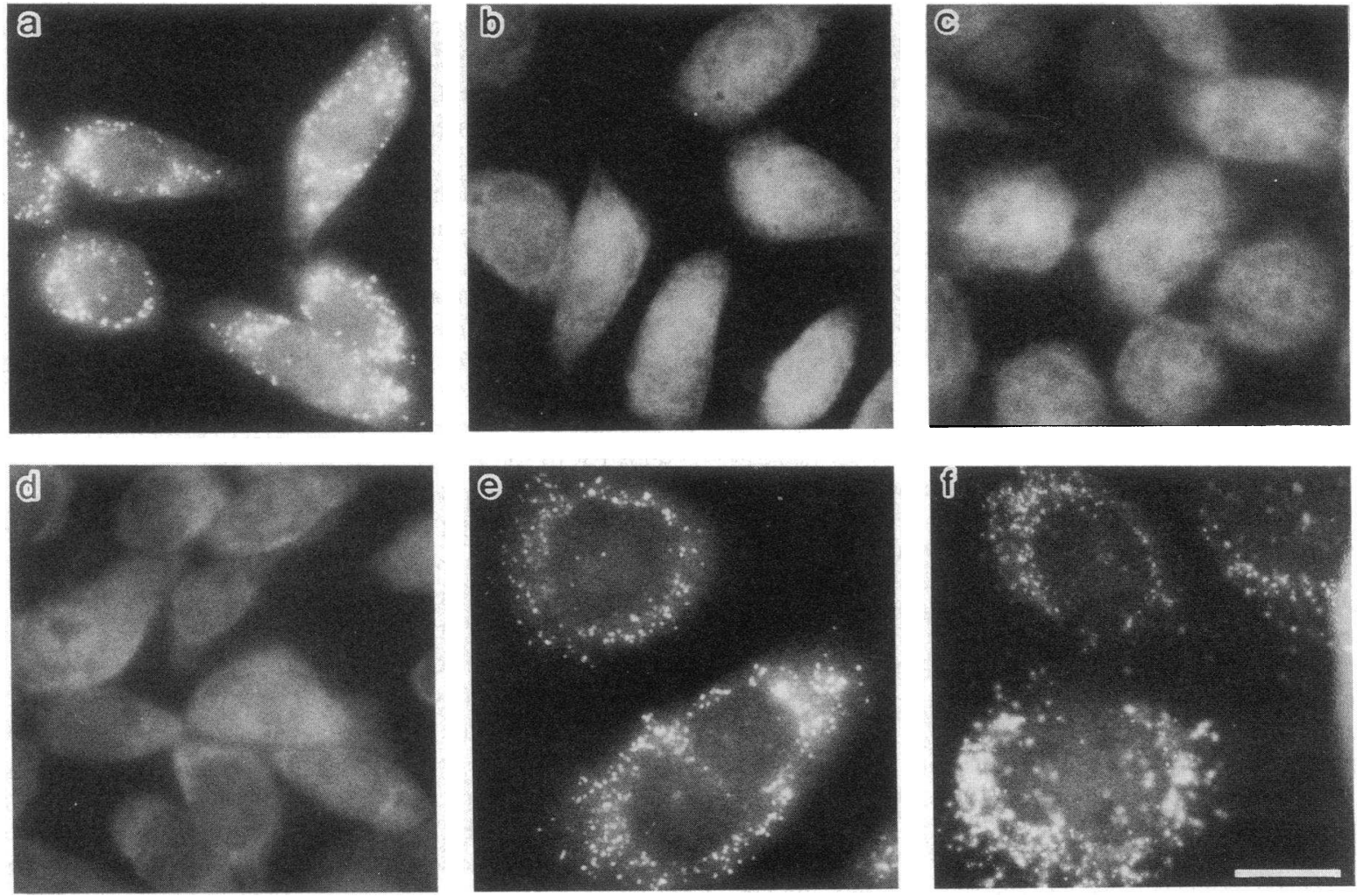

B
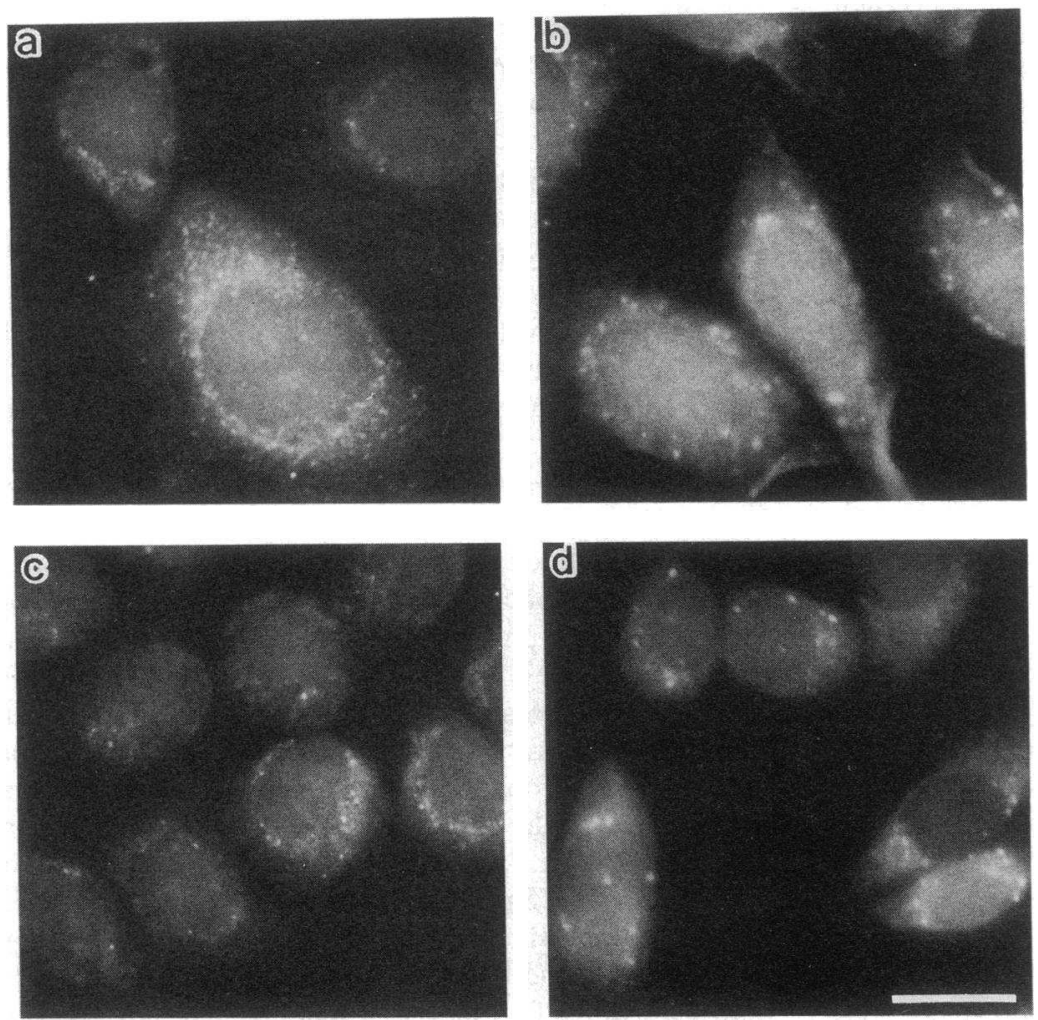

Figure 2. Immunofluorescence staining of wild type, mutant, and hybrid CHO cells. $(A)$ Cells were incubated with rabbit anti-rat catalase antiserum; antigen-antibody complex was detected with FITC-conjugated goat anti-rabbit IgG antibody. $a$, wild type CHO cells; $b-d$, mutants Z24, $\mathrm{Z65}$, and ZP92, respectively; $e$ and $f$, hybrid cells of ZP92 with Z24TG ${ }^{\mathrm{r} O u a^{\mathrm{r}}}$ and Z65TG $\mathrm{TG}^{\mathrm{r}} \mathrm{Oua}^{\mathrm{r}}$, respectively. $(B)$ Cells stained with rabbit antiserum against $70 \mathrm{kD}$ rat peroxisomal integral membrane protein. $a$, wild type; $b-d$, mutants $\mathrm{Z24}, \mathrm{Z65}$, and $\mathrm{ZP} 92$, respectively. Bar, $20 \mu \mathrm{m}$. 
Table I. Characteristics of Peroxisome-deficient CHO Mutants

\begin{tabular}{lcccc}
\hline CHO cell & $\begin{array}{c}\text { Peroxisomal } \\
\text { DHAP-ATase }\end{array}$ & $\begin{array}{c}\text { Catalase } \\
\text { latency }\end{array}$ & P12/UV & P9OH/UV \\
\hline Wild type & $285^{*}$ & $67^{\ddagger}$ & 87 & $\%$ \\
Z24 & $7^{*}$ & 0 & 4.1 & 80 \\
Z65 & $1^{*}$ & $0^{\ddagger}$ & 0.007 & 82 \\
ZP92 & 0 & 0 & $<0.001$ & 86 \\
& & & & \\
\hline
\end{tabular}

DHAP-ATase was measured as described (10); catalase latency, measured at $100 \mu \mathrm{g} / \mathrm{ml}$ of digitonin, was expressed as a percentage $(100 \%$, relative free catalase activity [10]). For determination of P12/UV and $\mathrm{P} 9 \mathrm{OH} / \mathrm{UV}$ resistance, 200 or $1 \times 10^{5}$ cells were inoculated and selected as described in Methods; the survival rate was expressed as a percentage of the unselected control. ${ }^{* \neq}$ From (10) and (12), respectively.

groups $\mathrm{C}$ and $\mathrm{E}$ in Japan (American groups 4 and 1), respectively (Fig. 4, $h$ and $i$ ). The results strongly suggest that $\mathrm{CHO}$ mutants ZP92 and Z24 are in the same complementation groups as $C(4)$ and $E(1)$, respectively. It is of interest to note that nuclei in the fused cells appeared to be stained in a diffused manner, although the reason is unknown.

The results obtained by morphological method in complementation analysis were assessed by biochemical studies on the biogenesis of AOx and thiolase. In the fused cells of ZP92 with ZS fibroblasts from group $\mathrm{C}$, only the $\mathrm{A}$ component of $\mathrm{AOx}$ was noted, as seen in the unfused ZS fibroblasts from groups B and $C$ (Fig. $5 A$, lanes 2, 3, and 5). Proper proteolytic conversion of $\mathrm{AOx}$ was apparent in the fibroblasts from a control and the hybrids such as that of Z65 cells with ZS fibroblasts of group B (lanes 1 and 4). In the hybrid cells of ZP92 and ZS fibroblasts of group $C$, thiolase was detected as a precursor in both Chinese hamster and human forms, as noted in ZP92 and fibroblasts of ZS patients (Fig. $5 \mathrm{~B}$, lanes 2, 4, 5, and 7). The thiolase precursor was also seen in the fused cells of Z24 with fibroblasts from a ZS patient of group $E$ (the same as group 1) (not shown). Processing of thiolase precursor was evident in the wild type CHO cells, human control fibroblasts, and the hybrids including that of Z65 with ZS fibroblasts of group B (lanes 1,3 , and 6 ). It is noteworthy that both a precursor and a processed form of thiolase of $\mathrm{CHO}$ cells were apparently faster in migration in SDS-PAGE than their human counterparts.

Taken together, CHO cell mutants ZP92 and Z24 appear to belong to the same complementation groups as fibroblasts from patients with $\mathrm{ZS}$ of complementation groups $\mathrm{C}$ and $\mathrm{E}$ (the same as group 4 and 1), respectively.

\section{Discussion}

The primary etiology of generalized peroxisomal disorders such as ZS is unknown, where four to eight complementation groups have been reported (4-6). To search for pathogenic gene(s) responsible for such disorders with the use of a somatic animal cell model, we previously isolated two peroxisome-deficient CHO cell mutants, Z24 and Z65 (10). Biogenesis of peroxisomes was restored by PAF-1 in Z65 (12). Formation of peroxisomes was restored in Z65, after cell-fusion with all of eight complementation groups of ZS fibroblasts, indicating that $\mathrm{Z65}$ belongs to a complementation group distinct from any group of human ZS fibroblasts. Zoeller et al. (11) also noted that their isolates of CHO mutants, ZR78 and ZR82, are in neither of the two groups 1 and 4 in the U.S. (5)( the same as E and C, respectively), of cells from ZS patients. Roscher et al. (5) suggested that the fibroblasts of their groups 1 and 2 correspond to those of groups 2 and 4 of Brul et al. (4).

We made use of a selection (not screening $[10,19]$ ) procedure of Morand et al. (13) to further isolate $\mathrm{CHO}$ cell mutants defective in peroxisome biogenesis. We isolated eight independent, apparently $\mathrm{P} 9 \mathrm{OH} / \mathrm{UV}$-resistant, and peroxisome-deficient mutant cell clones, in which seven were found to be in the same complementation group as Z65 (not shown). One mutant ZP92 was in the third group; no mutant belonging to the complementation group of $\mathrm{Z} 24$ was isolated in this study. Gene lesions in Z65-type mutant cells may occur with higher frequency than those in other types of $\mathrm{CHO}$ mutants, presumably all resulting in dysfunction of PAF-1. Very similar to Z24 and $Z 65$, the mutant ZP92 was defective in assembly of peroxisomes, albeit normal biosynthesis of peroxisomal proteins. Fu-

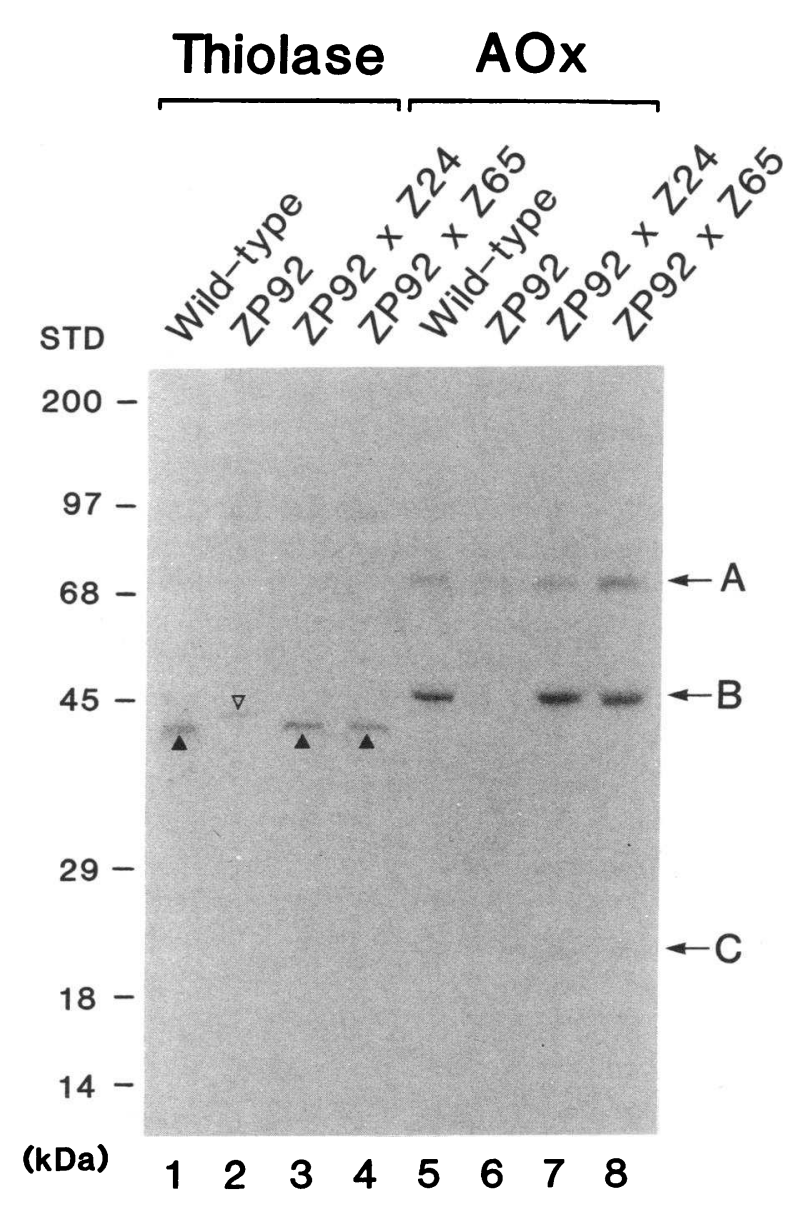

Figure 3. Biosynthesis of peroxisomal proteins in wild type, mutant and hybrid $\mathrm{CHO}$ cells. Cells were labeled for $48 \mathrm{~h}$ with [ $\left.{ }^{35} \mathrm{~S}\right]-$ methionine. Immunoprecipitation from cell lysates $\left(3 \times 10^{6}\right.$ disintegrations per minute) was done with anti-rat AOx and anti-rat thiolase antibodies, respectively. Immunoprecipitates were analyzed by SDS-PAGE and fluorography. Biogenesis in the wild type CHO cells (lanes 1 and 5), a mutant ZP92 (lanes 2 and 6 ), and fused cells between ZP92 and Z24 (lanes 3 and 7) or Z65 (lanes 4 and 8). Solid and open arrowheads indicate mature thiolase and its larger precursor, respectively; arrows show the migration of AOx components (see text). Molecular mass standards (STD) are on the left. Exposure, $8 \mathrm{~d}$. 

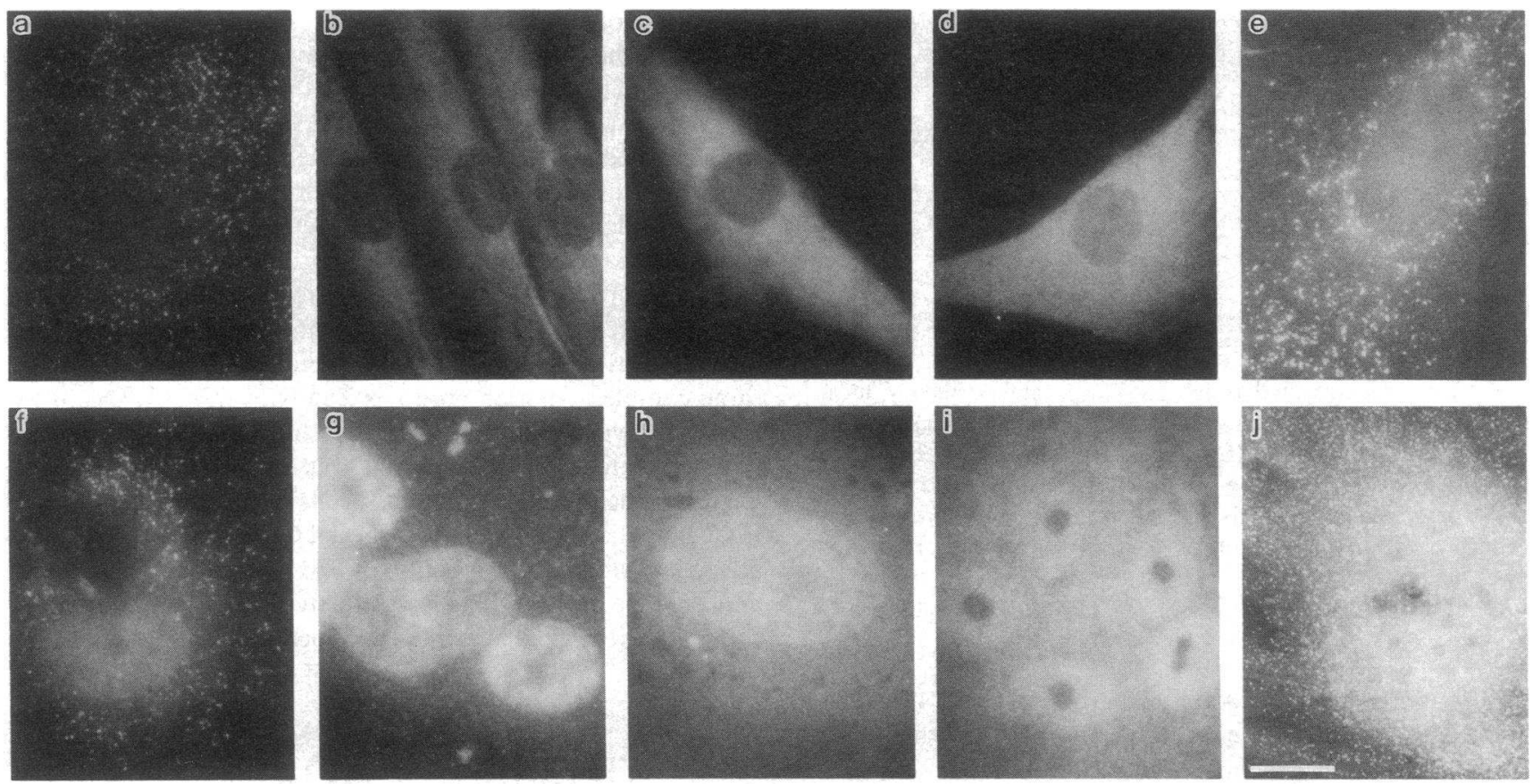

Figure 4. Immunofluorescence staining of human fibroblasts and their hybrids with $\mathrm{CHO}$ mutants. Cells were stained with rabbit antisera against human catalase $(a-d)$ and rat catalase $(e-j) . a-d$, Fibroblasts from a control and patients with ZS, groups B, C, and E (1), respectively; $e$ and $f$, hybrid cells of fibroblasts from a ZS patient from group B with CHO mutants Z65 and ZP92, respectively; $g$ and $h$, fused cells of ZS fibroblasts of group C with CHO mutants Z24 and ZP92, respectively; $i$ and $j$, hybrid cells of ZS patient fibroblasts of group E with Z24 and ZP92, respectively. No punctate peroxisomal staining was noted in $b, c, d, h$, and $i$. Bar, $20 \mu \mathrm{m}$.

sion of ZP92 with Z24 and Z65, respectively, resulted in apparently normal appearance in number and size of peroxisomes and appropriate proteolytic, intraperoxisomal $(16,17)$, processing of peroxisomal enzyme proteins, $\mathrm{AOx}$ and thiolase. These results imply that the genetic lesion in ZP92 differs from those of Z24 and Z65, while the phenotypes of these three mutants are very similar, including those such as deficiency in DHAP-ATase, sensitivity to P12/UV treatment, and P9OH/ UV resistance, all presumably caused by the absence of peroxisomes.

Large but fewer empty membranous vesicles, peroxisomal ghosts, are detectable in fibroblasts from ZS patients $(8,9)$. We noted ghostlike structures in all of the three $\mathrm{CHO}$ mutants, as seen in CHO mutants of one complementation group (11). The peroxisomal ghosts in $\mathrm{Z} 65$ may become competent, after expression of PAF-1, in translocation of newly synthesized proteins to form normal peroxisomes (12). It is likely that peroxisomal ghosts divide through cell division, based on the notion of constant appearance of such structures in peroxisome-deficient $\mathrm{CHO}$ mutants, as well as in the fibroblasts from ZS patients. Peroxisomal ghosts may be related to clinical manifestations, although they need to be further characterized in morphological and biochemical details.

A complete set of cell fusion analyses among three groups of CHO mutants and eight groups of fibroblasts from ZS patients led us to finding that two CHO mutants, Z24 and ZP92, are in the same complementation groups as human fibroblasts of groups $\mathrm{E}(1)$ and $\mathrm{C}(4)$, respectively. Respective genetic le$\operatorname{sion}(\mathrm{s})$ are likely in the same allele each in these two complementation groups of mutants and ZS fibroblasts. Taken together, nine complementation groups are evident in $\mathrm{CHO}$ mutants and ZS fibroblasts reported here; at least nine genes or their products, one of which is PAF-1, are apparently required for assembly of peroxisomes. Gene transfection and genetic complementation analysis using these two $\mathrm{CHO}$ mutants, Z24

Table II. Complementation Analysis between CHO Mutants and Human Fibroblasts from Patients with Generalized Peroxisome-deficient Disorders

\begin{tabular}{cllll}
\hline $\begin{array}{c}\text { Human } \\
\text { fibroblast }\end{array}$ & Phenotype & Z24 & Z65 & ZP92 \\
\hline Group A & ZS & + & + & + \\
B & ZS & + & + & + \\
C (4) & ZS* & + & + & - \\
D & ZS & + & + & + \\
E (1) & NALD & - & + & + \\
& ZS & - & + & + \\
2 & ZS & + & + & + \\
3 & ZS & + & + & + \\
6 & NALD & + & + & + \\
F & ZS & + & - & + \\
\hline
\end{tabular}

NALD, neonatal adrenoleukodystrophy. ${ }^{* \pm}$ Fibroblasts from three patients each of group $\mathrm{C}$ and group 1 were tested. + , complemented; - , not complemented. Human fibroblasts from patients with peroxisomal disorders [see ref. 6 for groups A-E; ref. 5 for 1-4 and 6] were fused with a respective variant, $\mathrm{TG}^{\mathrm{r}}$, of $\mathrm{CHO}$ cell mutants, $\mathrm{Z24}, \mathrm{Z65}$, and ZP92, and the hybrid cells were selected in the presence of hypoxanthine/aminopterin/thymidine plus ouabain (see Methods). The hybrid cells were assayed for presence of peroxisomes, by immunofluorescent staining. Note that complementation groups 1 and 2 are suggested by Roscher et al. (5) to be the same as groups 2 and 4 , respectively, of (4); the result of cell fusion analysis of group $F$ with three CHO mutants is from reference (23). 


\section{A Acyl-CoA Oxidase}

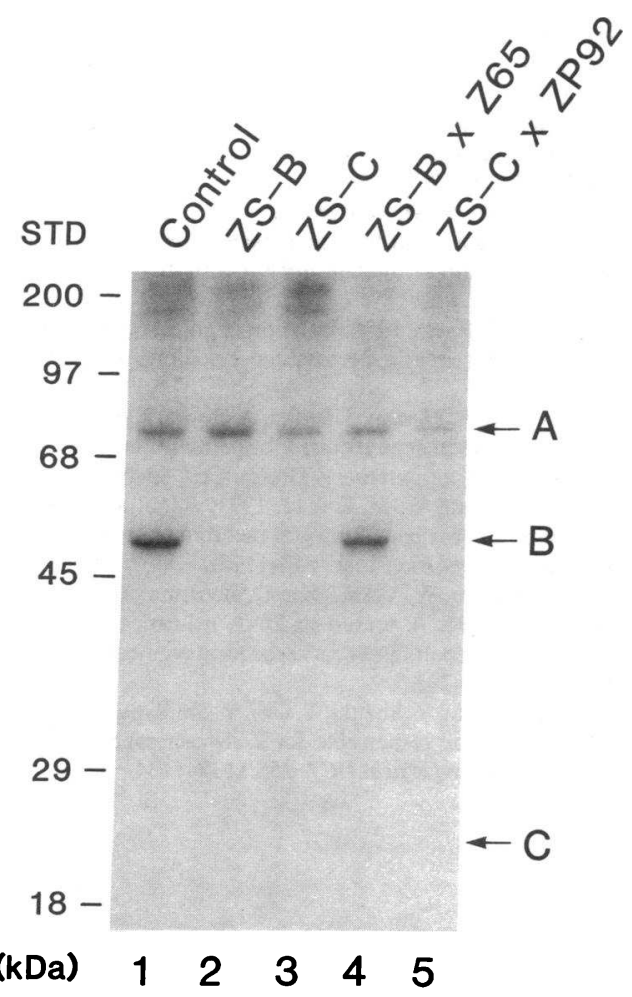

\section{B Thiolase}

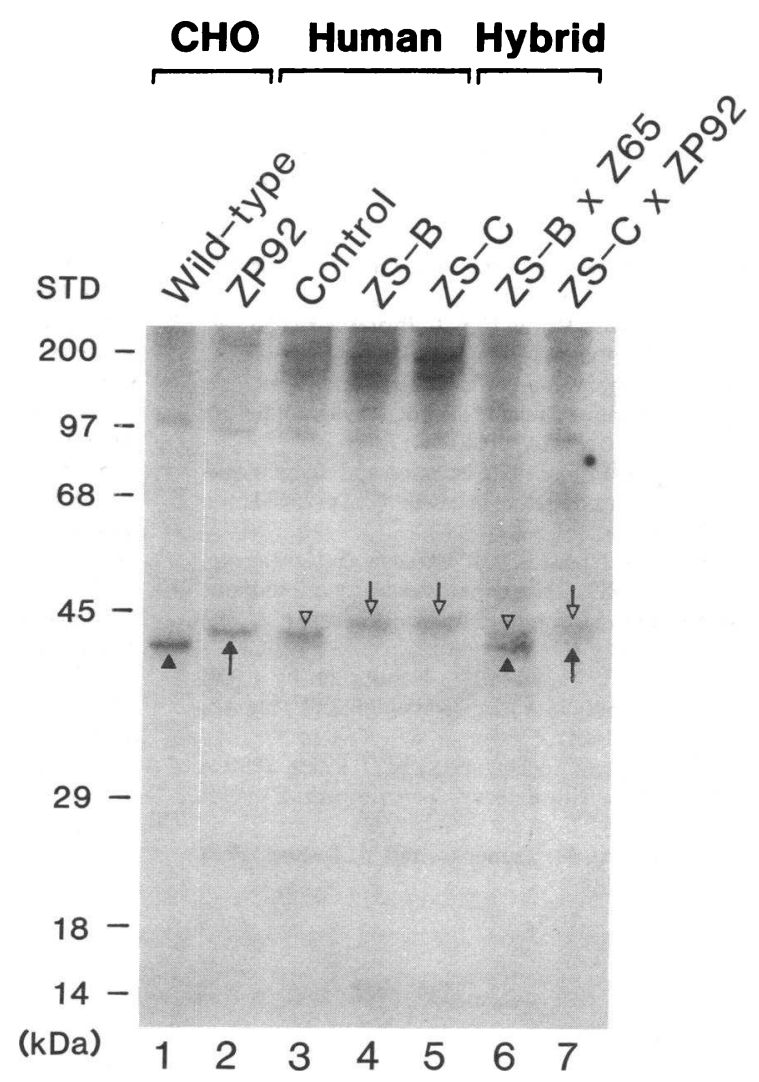

Figure 5. Biogenesis of acyl-CoA oxidase and thiolase in $\mathrm{CHO}$ cells, human fibroblasts, and their hybrids. Cell labeling and immunoprecipitation were done as in Fig. 3. (A) Lanes 1-3, fibroblasts from a control and ZS patients of complementation groups $\mathrm{B}$ and $\mathrm{C}$, respectively; lanes 4 and 5 , hybrid cells of CHO mutants Z65 and ZP92 with ZS fibroblasts of groups B and C, respectively. (B) CHO cells (lanes 1 and 2); human fibroblasts (lanes 3-5); and hybrids of $\mathrm{CHO}$ and human cells (lanes 6 and 7). Solid arrowhead (lanes 1 and 6 ) and arrow (lanes 2 and 8 ) indicate mature thiolase and its precursor of $\mathrm{CHO}$ cells, respectively; open arrowhead (lanes 3 and 6 ) and open arrow (lanes 4, 5, and 7) show human mature thiolase and its precursor, respectively. Note the difference in migration of $\mathrm{CHO}$ and human thiolases. Exposure, $20 \mathrm{~d}$.

and ZP92, may lead to identification of pathogenic genes in ZS of groups $E(1)$ and $C(4)$, respectively, as proven to be useful in the case of cDNA cloning of PAF-1 (12).

In the yeast Saccharomyces cerevisiae, two genes (pas-1 and pas-3) essential for peroxisome biogenesis have been identified $(20,21)$. The deduced amino acid sequences of pas-1 and pas -3 are distinct from that of PAF-1 cDNA. Isolation of mammalian homologues of pas-1 and -3 might be useful for investigation of the primary etiology of peroxisome-deficient disorders. Similar type of gene cloning with somatic animal cell mutants has been successful for delineation of the primary defects in human diseases, where only clinical phenotypes are evident. For instance, a human gene was cloned for DNA excision repair in xeroderma pigmentosum of group $\mathrm{C}$ by genetic complementation assay using a CHO mutant (22).

Very recently, a female infant was diagnosed with a case of typical ZS but could not be classified into any of the previous, eight complementation groups of peroxisome-deficient disorders. Fibroblasts from this patient appeared to be in the same complementation group as that of Z65; rat PAF- 1 restored the assembly of peroxisomes in the fibroblasts. The primary defect of Zellweger syndrome in this patient was a point mutation in PAF-1 gene that caused a premature termination of PAF-1 (23).

\section{Acknowledgments}

The authors thank I. Kasuya-Arai for her technical assistance, H. W. Moser for fibroblasts from patients with peroxisome-deficient disorders, and T. Hashimoto for anti-human catalase antibody.

This work was supported in part by grants from the National Center of Neurology and Psychiatry (2-A-6) and Uehara Memorial Foundation and Pediatric Research (63-A) from the Ministry of Health and Welfare, Japan, and by Grants-in-Aid for Scientific Research (03770558).

\section{References}

1. Fahimi, H. D., and H. Sies. 1987. In Peroxisomes in Biology and Medicine. Springer-Verlag, Berlin. $470 \mathrm{pp}$.

2. Lazarow, P. B., and H. W. Moser. 1989. Disorders of peroxisome biogenesis. In The Metabolic Basis of Inherited Disease. 6th ed. C. R. Scriver, A. I Beaudet, W. S. Sly, and D. Valle, editors. McGraw-Hill Inc., New York. 14791509.

3. Schutgens, R. B. H., H. S. A. Heymans, R. J. A. Wanders, H. van den Bosch, and J. M. Tager. 1986. Peroxisomal disorders: a newly recognized group of genetic diseases. Eur. J. Pediatr. 144:430-440.

4. Brul, S., A. Westerweld, A. Strijland, R. J. A. Wanders, A. W. Schram, H. S. A. Heymans, R. B. H. Schutgens, H. van den Bosch, and J. M. Tager. 1988. Genetic heterogeneity in the cerebrohepatorenal (Zellweger) syndrome and other inherited disorders with a generalized impairment of peroxisomal functions. A study using complementation analysis. J. Clin. Invest. 81:1710-1715.

5. Roscher, A. A., S. Hoefler, G. Hoefler, E. Paschke, F. Paltauf, A. Moser, and H. Moser. 1989. Genetic and phenotypic heterogeneity in disorders of perox- 
isomal biogenesis. A complementation study involving cell lines from 19 patients. Pediatr. Res. 26:67-72.

6. Yajima, S., Y. Suzuki, N. Shimozawa, S. Yamaguchi, T. Orii, Y. Fujiki, T. Osumi, T. Hashimoto, and H. W. Moser. 1992. Complementation study of peroxisome-deficient disorders by immunofluorescence staining and characterization of fused cells. Hum. Genet. 88:491-499.

7. Goldfischer, S., C. L. Moore, A. B. Johnson, A. J. Spiro, M. P. Valsamis, H. K. Wisniewski, R. H. Ritch, W. T. Norton, I. Rapin, and L. M. Gartner. 1973. Peroxisomal and mitochondrial defects in the cerebro-hepato-renal syndrome. Science (Wash. DC). 182:62-64.

8. Santos, M. J., T. Imanaka, H. Shio, G. M. Small, and P. B. Lazarow. 1988. Peroxisomal membrane ghosts in Zellweger syndrome. Aberrant Organelle Assembly. Science (Wash. DC). 239:1536-1538.

9. Wiemer, E. A. C., S. Brul, W. W. Just, R. van Diel, E. Brouwer-Kelder, M. van den Berg, P. J. Weijers, R. B. H. Schutgens, H. van den Bosch, A. Schram, et al. 1989. Presence of peroxisomal membrane proteins in liver and fibroblasts from patients with the Zellweger syndrome and related disorders: evidence for the existence of peroxisomal ghosts. Eur. J. Cell Biol. 50:407-417.

10. Tsukamoto, T., S. Yokota, and Y. Fujiki. 1990. Isolation and characterization of Chinese hamster ovary cell mutants defective in assembly of peroxisomes. J. Cell Biol. 110:651-660.

11. Zoeller, R. A., L.-A. H. Allen, M. J. Santos, P. B. Lazarow, T. Hashimoto, A. M. Tartakoff, and C. R. H. Raetz. 1989. Chinese hamster ovary cell mutants defective in peroxisome biogenesis. Comparison to Zellweger syndrome. J. Biol. Chem. 264:21872-21878.

12. Tsukamoto, T., S. Miura, and Y. Fujiki. 1991. Restoration by a 35K membrane protein of peroxisome assembly in a peroxisome-deficient mammalian cell mutant. Nature (Lond.). 350:77-81.

13. Morand, O. H., L.-A. H. Allen, R. A. Zoeller, and C. R. H. Raetz. 1990. A rapid selection for animal cell mutants with defective peroxisomes. Biochim. Biophys. Acta. 1034:132-141.

14. Suzuki, Y., S. Yamaguchi, T. Orii, M. Tsuneoka, and Y. Tashiro. 1990.
Nonspecific lipid transfer protein (sterol carrier protein 2 ) defective in patients with deficient peroxisomes. Cell Struct. Funct. 15:301-308.

15. Miyazawa, S., H. Hayashi, M. Hijikata, N. Ishii, S. Furuta, H. Kagamiyama, T. Osumi, and T. Hashimoto. 1987. Complete nucleotide sequence of cDNA and predicted amino acid sequence of rat acyl-CoA oxidase. J. Biol. Chem. 262:8131-8137.

16. Miura, S., M. Mori, M. Takiguchi, M. Tatibana, S. Furuta, S. Miyazawa, and T. Hashimoto. 1984. Biosynthesis and intracellular transport of enzymes of peroxisomal $\beta$-oxidation. J. Biol. Chem. 259:6397-6402.

17. Miyazawa, S., T. Osumi, T. Hashimoto, K. Ohno, S. Miura, and Y. Fujiki. 1989. Peroxisome targeting signal of rat liver acyl-coenzyme A oxidase resides a the carboxy terminus. Mol. Cell. Biol. 9:83-91.

18. Fujiki, Y., R. A. Rachubinski, R. M. Mortensen, and P. B. Lazarow. 1985. Synthesis of 3-ketoacyl-CoA thiolase of rat liver peroxisomes on free polyribosomes as a larger precursor. Induction of thiolase mRNA activity by clofibrate. Biochem. J. 226:697-704.

19. Zoeller, R. A., and C. R. H. Raetz. 1986. Isolation of animal cell mutants deficient in plasmalogen biosynthesis and peroxisome assembly. Proc. Natl. Acad. Sci. USA. 83:5170-5174.

20. Erdmann, R., F. F. Wiebel, A. Flessau, J. Rytka, A. Beyer, K.-U. Frölich, and W.-H. Kunau. 1991. PASI, a yeast gene required for peroxisome biogenesis, encodes a member of a novel family of putative ATPases. Cell. 64:499-510.

21. Höhfeld, J., M. Veenhuis, and W.-H. Kunau. 1991. PAS3, a Saccharomyces cerevisiae gene encoding a peroxisomal integral membrane protein essential for peroxisome biogenesis. J. Cell Biol. 114:1167-1178.

22. Weeda, G., R. C. A. van Ham, W. Vermeulen, D. Bootsma, A. J. van der Eb, and J. H. J. Hoeijmakers. 1990. A presumed DNA helicase encoded by $E R C C-3$ is involved in the human repair disorders xeroderma pigmentosum and Cockayne's syndrome. Cell. 62:777-791.

23. Shimozawa, N., T. Tsukamoto, Y. Suzuki, T. Orii, Y. Shirayoshi, T. Mori, and Y. Fujiki. 1992. A human gene responsible for Zellweger syndrome that affects peroxisome assembly. Science (Wash. DC). 255:1132-1134. 